\title{
ÉTICA E DESENVOLVIMENTO SUSTENTÁVEL ${ }^{1}$
}

\author{
Daniel Arruda Coronel ${ }^{2}$ \\ José Maria Alves da Silva
}

Resumo: O objetivo deste artigo é tecer considerações hermenêuticas e filosóficas sobre ética, economia e meio ambiente, enfocando, especificamente, a relação entre o imperativo categórico formulado por Kant e a questão do desenvolvimento sustentável. Para isso, considerou-se como elemento de ligação a perspectiva econômica de GeorgescuRoegen. Embora a economia, a ética e a biologia constituam campos distintos de especialização, o trabalho procurou mostrar as razões pelas quais essa perspectiva pode ser vista como uma área de interseção entre essas três disciplinas. Conclui-se que as recomendações de Georgescu-Roegen, contidas no seu chamado "programa bioeconômico mínimo", estão de acordo com os preceitos fundamentais da ética kantiana, no que diz respeito à questão do desenvolvimento sustentável.

Palavras-chave: ética, desenvolvimento sustentável, Kant, Georgescu-Roegen, bioeconomia.

\section{Introdução}

Ultimamente, a questão do desenvolvimento sustentável tem merecido grande destaque na imprensa, com as recentes publicações de relatórios internacionais e suas alarmantes conclusões sobre os problemas climáticos do planeta. Frequentemente, os alertas desses estudos são divulgados pela mídia de forma alarmista, sem levar na devida consideração certas questões que estão no cerne do problema.

Recebido em: 02/09/09; Aceito em: 10/12/09.

2 Doutorando em Economia Aplicada pela Universidade Federal de Viçosa (UFV).

E-mail: daniel.coronel@ufv.br.

3 Professor Associado da UFV, Doutor em Economia pela Universidade de São Paulo (USP).

E-mail: jmasilva@ufv.br. 
Na década de 70, começa a ficar latente a preocupação com o desenvolvimento sustentável por meio da publicação, por parte do Clube de Roma ${ }^{4}$, da obra Limites ao Crescimento, que definiu cinco pontos inibidores do crescimento econômico: população, produção agrícola, recursos naturais, produção industrial e contaminação. A partir daí, foram crescendo as discussões e os debates acerca do desenvolvimento sustentável, sendo generalizado o seu conceito a partir do relatório Brundtland (1987) e atingindo o ápice na Conferência das Nações Unidas sobre o Meio Ambiente e o Desenvolvimento, no Rio de janeiro, em 1992, na qual se define a Agenda 21, ou seja, um conjunto de pressupostos que as nações deveriam adotar visando à sustentabilidade.

No Relatório Brundtland, desenvolvimento sustentável é definido como desenvolvimento "que atende às necessidades do presente sem comprometer a possibilidade de as gerações futuras atenderem às suas próprias necessidades" (WORLD COMMISSION ON ENVIRONMENT and DEVELOPMENT, 1987). A partir desse conceito, a discussão tem evoluído e, quase sempre, gira em torno da busca de um suposto equilíbrio entre as dimenssões econômica, social e ambiental.

Seja no nível das nações (GLADWIN et al., 1995; BANERJEE, 2003; GREAKER, 2003; ANTON et al., 2004; SPANGENBERGER, 2004), seja no nível da gestão empresarial (BUYSSE; VERBEKE, 2003; RUSSO, 2003; BANSAL, 2005; SHARMA; HENRIQUES, 2005; e BARIN-CRUZ et al., 2006), o desenvolvimento sustentável entrou na pauta das preocupações de gestores públicos e privados. Mais que isso, ele começa a ser compreendido e discutido de forma cada vez mais difusa na sociedade.

\footnotetext{
O Clube de Roma surgiu em 1968, formado por cientistas de diversas nacionalidades, com o objetivo de discutir os problemas que afligiam a humanidade e, a partir de políticas concretas, visar ao equacionamento desses problemas.
} 
Considerando a ética individual a partir do imperativo categórico kantiano, o comportamento de cada indivíduo deveria basear-se na seguinte máxima: ages de tal modo que a máxima das tuas ações possa tornar-se uma lei universal, ou, ainda, ages de maneira que o motivo que te levou a agir assim possa ser convertido em lei universal. Seria, então, plausível considerar o desenvolvimento sustentável a partir do imperativo categórico kantiano? Se sim, quais seriam suas implicações?

Este artigo se desenvolve sobre tais premissas. Numa perspectiva transdisciplinar, visa mostrar as relações e implicações entre desenvolvimento sustentável, bioeconomia de Georgescu-Roegen e imperativo categórico de Kant. Para tanto, o texto está dividido em quatro seções, além desta introdução. Na segunda seção, define-se e classifica-se o conceito de ética e seu objeto, como disciplina filosófica, além da relação com as outras áreas do conhecimento e sua evolução desde a Grécia antiga até os dias atuais. Na terceira seção, a partir das definições convencionais, o conceito de desenvolvimento sustentável é revisto sob a ótica de Georgescu-Roegen. Na quarta seção, estabelecese uma relação entre o imperativo categórico e a bioeconomia e, por fim, são apresentadas algumas considerações e conclusões gerais sobre as questões levantadas.

\section{2. $O$ conceito de ética}

Pode-se definir ética como a disciplina que trata do agir humano e de suas regras ou princípios ou ideais, com vistas em determinar qual a melhor forma de agir, individualmente ou socialmente, na relação entre os homens, ou seja, a ética implica uma relação com o outro ser.

Segundo Vázquez (2006, p.23), “ a ética é a teoria ou ciência do comportamento moral dos homens em sociedade, ou seja, é ciência de uma forma específica de comportamento humano". 
O objeto de estudo e as pesquisas que envolvem a ética têm como foco os atos humanos, ou seja, os atos humanos voluntários e conscientes que afetam outros indivíduos, outros grupos sociais e outras pessoas.

Na filosofia tradicional, segundo Napoli (2000) e Vázquez (2006), a ética é classificada em três tipos: Ética Descritiva, Ética Normativa e Metaética. A primeira está relacionada com questões empíricas, ou seja, com princípios e valores de determinada época ou lugar, sem se preocupar em estabelecer juízos sobre o que é certo ou errado, ou seja, sem entrar na essência, na phýsis do problema. A Ética Nomativa está relacionada com questões abstratas do agir humano, isto é, de acordo com Vázquez (2006), a concepção normativa tem como pressuposto fazer recomendações, formular normas, contudo, essas recomendações não atingem a teoria ética, que pretende explicar o sustentáculo da moral relacionado com as ações do homem. Por Metaética, de acordo com Napoli (2000), compreende-se o nível lógico das afirmações e proposições conceituais, ou seja, tipo de reflexão que analisa o discurso moral, constituindo uma metalinguagem de caráter intencionalmente neutro ou não-normativo.

As questões éticas, apesar de serem mais estudadas pelos filósofos, não podem ser usurpadas pela filosofia, de acordo com Mendonça (2003), visto que envolvem conceitos transdiciplinares como liberdade, justiça, sociabilidade, sustentabilidade, valor, necessidade etc., partilhados com diferentes áreas do conhecimento.

O direito está intimamente ligado à ética, visto que visa à justiça e ao bem comum, e a justiça é o centro da reflexão e dos problemas éticos. A ética está, gnosiologicamente, entrelaçada com a Psicologia, com a Sociologia e com a Antropologia, visto que a Psicologia possibilita a compreensão dos atos e atitudes do homem e contribui para explicar os atos humanos na dimensão moral. Já a Antropologia e a Sociologia estão relacionadas com a ética, visto que estudam o comportamento do homem como ser social, como ele está inserido na sociedade e qual a sua forma de relação com outros indivíduos (VAZQUEZ, 2006). 
A relação entre ética e Ciências Sociais aplicadas foi tratada por Max Weber. Na obra "Ética Protestante e Espírito do Capitalismo" (Weber, 2006), o capitalismo é apresentado como ordem social, respaldado por uma doutrina ontologicamente desligada dos dogmas do catolicismo medieval e validado por uma ética favorável aos interesses capitalistas.

Na Medicina, o conceito de ética está relacionado com a Bioética, que, segundo Loreto (2003), deve ser entendida como as condições necessárias para uma administração responsável da vida humana, considerando a responsabilidade moral dos cientistas e pesquisadores com a vida humana.

O conceito de ética remonta à Grécia antiga. No entanto, no curso da história, com a evolução da ciência e com a sistematização do conhecimento, sofreu várias transormações, sem perder, contudo, sua essência.

Na Grécia antiga, observa-se, com base nos pressupostos filosóficos dos sofistas ${ }^{5}$, Sócrates (2002), Platão (2004) e Aristóteles (2004), três vertentes de ética: a do movimento dos sofistas, com ênfase na utilização da ética e da retórica para persuadir e obter êxito na vida política; a de Sócrates (2002), com ênfase nas virtudes e na bondade, ou seja, o homem, ao conhecer o bem e as virtudes, vai procurar agir de tal modo a praticálas; e a ética de Platão (2004) e Aristóteles (2004), relacionada com a política e com as virtudes morais dos deveres e direitos cívicos.

Na Idade Média, de acordo com Spinelli (2002), o conceito de ética estava relacionado com a filosofia cristã, ou seja, um conjunto de pressupostos e verdades a respeito de Deus, os quais o homem deveria seguir para atingir a salvação e a contemplação divina. A ética cristã tende a regular os atos, as atitudes e o pensamento das pessoas com vistas em outro mundo, colocando Deus como fim, como senhor de todas as coisas e de todas as pessoas.

\footnotetext{
De acordo com Spinelli (1998), podem-se definir os sofistas como um movimento intelectual da Grécia Antiga, mas que perdeu sua essência ao tentar utilizar-se do conhecimento e da retórica para persuasão e obtenção de privilégios e de riqueza.
} 
A ética moderna, de acordo com Vázquez (2006), tem um novo redimensionamento, pois desaparece a visão cristã da ética com foco em Deus e observa-se uma visão com ênfase no homem, ou seja, uma visão antropocêntrica que tenha o homem como centro e fundamento do universo, embora ele se conceba de maneira abstrata, dotado de uma natureza universal e imutável. Na ética moderna vão se destacar os pressupostos ético-filosóficos de Kant (2003) e Weber (2006).

Para Kant (2003), ética consiste em não tomar as pessoas como meio ou como fim. A ética kantiana é autônoma e formal, na medida em que formula para os homens um dever independente de suas condições sociais e econômicas, já que este é um ser livre, ativo, produtor e criador.

As ideias de Kant são um resultado lógico de sua crença na liberdade fundamental do indivíduo, como afirmada na sua Crítica da Razão Prática (2004). Essa liberdade não pode ser confundida como anarquismo, mas deve ser entendida mais como a liberdade de autogoverno, a liberdade para obedecer, conscientemente, as leis universais como reveladas pela razão.

A ética protestante, formulada por Weber, foi ao encontro e aos anseios da burguesia capitalista europeia, justificando as ações do homem em busca do lucro e da riqueza, ou seja, as ideias weberianas foram o sustentáculo teórico para o fortalecimento do sistema capitalista. Ainda nessa perspectiva, de acordo com Cherques (1997, p. 13), ao estudar a ética protestante, Weber pretendeu explicar o capitalismo moderno mediante a análise das possibilidades de sua gênese.

A Ética contemporânea pode ser dividida em duas partes, quais sejam, a ética do século XX, que reproduz discussões filosóficas de temas como existencialismo e justiça social, e a do século XXI, que tem como preocupação o meio ambiente, o desenvolvimento sustentável, as desigualdades sociais, as questões políticas e a responsabilidade dos homens com o futuro da sociedade 
O existencialismo tem uma nova conotação a partir dos pressupostos filosóficos de Sartre (1996), que concebe o homem como um ser livre por natureza, sendo que suas ações não são condicionadas às forças sociais, econômicas, físicas, culturais e psicológicas.

A relação entre ética e justiça social encontra os fundamentos teóricos em Ralws (2002), que concebe que o censo de justiça se manifesta de duas formas: quando as instituições justas que se aplicam a todos são aceitas, de modo que a aceitação e lealdade garantem que as rivalidades entre as pessoas serão tratadas de forma igual; e quando as pessoas se dispõem a trabalhar a favor de instituições justas e fazer as mudanças quando necessário. Quando se atinge a moralidade de princípios, o desenvolvimento moral está completo, e este pode assumir duas formas: a primeira corresponde ao sentimento de justo e de justiça; e a segunda, ao amor pela humanidade.

Para Ralws (2002), o pressuposto fundamental do censo de justiça é que cada pessoa deva ter a mais ampla liberdade, sendo que esta última deve ser igual à dos outros e a mais extensa possível, na medida em que seja compatível com uma liberdade similar à dos outros indivíduos.

Morin (2005), ao discutir as questões éticas, traz para o debate a autoética, ou seja, enfoca questões não mais ligadas à epistemologia da moral e da política, mas a elementos como responsabilidade social, cultural e educacional do homem com a sociedade em que vive, a capacidade de o homem fazer reflexões sobre a maneira que interage com a sociedade por meio de elementos como honra, tolerância, prática de responsabilidade, autocrítica e autoanálise.

A ética individualizada ou auto-ética é uma emergência, ou seja, uma qualidade que só pode aparecer em condições históricas e culturais de individualização comportando a erosão e, quase sempre, a dissolução das éticas tradicionais, isto é, a degradação do primado 
do costume, "regra primitiva do dever", o enfraquecimento do poder da religião, a diminuição (de resto bastante desigual) da presença intima em si do Superego cívico (MORIN, 2005, p.91).

Grande exemplo de preocupação ética e social do homem com a sociedade pode ser encontrado nas cartas de Albert Einstein e Sigmund Freud, de 1932, intituladas "Por que a Guerra?" ${ }^{\circ} \mathrm{Na}$ correspondência entre esses dois grandes personagens da história científica, observamse, sobretudo, a preocupação e as inquietudes de ambos quanto ao futuro das relações internacionais, mais especificamente com a capacidade da Liga das Nações em promover a paz e o desenvolvimento sustentável da sociedade, questões fora do contexto de suas respectivas áreas de trabalho e pesquisa. As preocupações e discussões éticas do novo milênio estão centradas em assuntos como igualdade de oportunidades e de direitos políticos e, principalmente, questões relacionadas com meio ambiente e conceito de desenvolvimento sustentável.

\section{Desenvolvimento sustentável}

Com Aristóteles, a economia surgiu como um ramo da ética: a ética do relacionamento nas atividades de sustentação da vida material (Ética a Nicômano, 2004). Portanto, na concepção aristotélica, o vínculo entre ética e desenvolvimento sustentável é inalienável, uma vez que as atividades de sustentação da vida material humana não são neutras em relação ao meio natural. Contudo, Aristóteles não tinha por objetivo a questão ambiental. Ele visava firmar uma ética da justiça, como bem mostra o seu princípio do comércio justo, segundo o qual a troca de mercadorias entre dois homens deve servir ao propósito de melhorar as condiçoes de vida de ambos e não constituir meio pelo qual um pudesse ser beneficiado em detrimento do outro. Assimilado pela doutrina cristã, o princípio aristotélico da troca justa foi incorporado na economia política durante séculos, até que, com o advento do Iluminismo, a economia passou

6 Para maior compreensão sobre os diálogos, as indagações entre Einsten e Freud, ver Seitenfus e Ventura (2005). 
a ser identificada com os conceitos de prazer e autointeresse, convertendo-se, cada vez mais, no que o próprio Aristóteles havia definido como "crematística não-natural", como pode ser obervado no livro "A Política, 2008”.

A preocupação com o meio ambiente é bem recente na história humana. Ela se manifesta, de forma mais difundida, na segunda metade do século XX. Os estudos de Carson (1962), Georgescu-Roegen (1971) e Schumacher (1983) contituem referências seminais sobre o tema do desenvolvimento sustentável. No livro Primavera Silenciosa, que se tornou best seller nos EUA, Rachel Carson relata os resultados de investigações sobre os efeitos de agentes químicos sintéticos nos organismos vivos. Esse trabalho constituiu um primeiro grande alerta para os perigos sanitários e riscos ambientais dos agrotóxicos. A comprovação das perturbações endócrinas provocadas pelo DDT e os danos ecológicos levaram a uma nova postura político-governamental com relação ao uso de agroquímicos, o que culminou na criação do Enviromental Pretecion Agency (EPA), pelo presidente John Kennedy.

O trabalho de E. F. Schumacher constituiu um dos primeiros desafios ao "mito do progresso econômico", ao chamar atenção para os impactos ambientais das grandes potências industriais, altamente intensivas em consumo de energia e geradoras de poluição. Sua mensagem mais contundente, apoiada por estatísticas energéticas, era simplesmente que o estilo de vida norte-americano não poderia ser tomado como referência mundial, visto que não poderia ser sustentado por muito tempo. Isso depunha fortemente contra a teoria neoclássica do crescimento econômico, que previa a convergência de renda entre os países. Como o trabalho de Schumacher veio deixar claro, o problema dessa teoria é que ela simplesmente desconsidera as restrições representadas pelos estoques de recursos naturais não renováveis, como carvão, petróleo e água.

Mas o tratamento mais geral, ou mesmo holístico, sobre a relação entre desenvolvimento econômico, ética e meio ambiente é fornecido pelo economista romeno radicado nos EUA, Nichollas Georgescu-Roegen (1906-1994), numa série de trabalhos fecundos e inovadores. Essa é 
razão pela qual, em vez de uma resenha multivariada e superficial de vários autores, optou-se, aqui, por um exame mais detalhado das contribuições desse importante autor sobre o tema em questão ${ }^{7}$.

Sua obra nesse campo constitui uma crítica substancial ao paradigma mecanicista, transplantado pelos fundadores da escola neoclássica, da física newtoniana para a economia, no qual o sistema econômico é representado como se fosse do tipo reprodutível, isto é, capaz de reproduzir toda a energia que consome. No entanto, isso se aplica apenas aos recursos trabalho e capital, que costumam aparecer, explicitamente, na função neoclássica de produção. O produto resultante da aplicação desses recursos pode ser usado para sustentá-los num nível constante ou crescente, ou seja, para recompor a energia gasta pelos trabalhadores no esforço produtivo e para repor o estoque de capital, em escala constante (reprodução estacionária) ou crescente (reprodução ampliada). Mas, nesse processo, o acervo de recursos naturais, como terra, água, florestas e minérios, necessariamente sofre uma degradação entrópica. No entanto, sua habitual omissão no argumento da função de produção parece pressupor que, enquanto o capital se acumula e a população cresce, "tudo o mais permanece constante".

Essa é a razão pela qual, como uma espécie de dissidente do mainstream neoclássico, do qual se afastou na década de 60, Georgescu-Roegen propôs para o sistema econômico a analogia dos sistemas entrópicos descritos pela física termodinâmica, em lugar do modelo neoclássico de inspiração mecanicista ${ }^{8}$.

\footnotetext{
Sobre a questão do desenvolvimento sustentável, as ideias de Georgescu-Roegen são extremamente inovadoras, a começar pela ideia de que, strictusensu, não existe desenvolvimento econômico autosustentável, levando-se em conta o sistema econômico não é como um sistema mecânico do tipo moto perpétuo, mas sim um processo evolutivo entrópico que caminha inexoravelmente para a extinção. Nesse sentido, a preservação ambiental não deve ter por objetivo a sustentabilidade absoluta, posto que é impossível, mas sim a maximização das possibilidades de vida no planeta.

8 Antes de sua conversão, Georgescu-Roegen foi um expoente da pesquisa teórica do mainstream neoclássico, tendo apresentado insights que inspiraram vários dos principais teoremas econômicos posteriormente desenvolvidos por outros eminentes neoclássicos, como Paul Samuelson. Para muitos, somente o conjunto de sua obra teórica na economia neoclássica teria sido suficiente para fazê-lo merecer a láurea do prêmio Nobel em economia.
} 
A idéia de que o processo econômico não é um análogo mecânico, mas uma transformação entrópica, unidirecional, começou a girar na minha mente, há muito tempo, quando testemunhei os poços de petróleo do campo secarem um a um e cresci consciente da luta dos camponeses romenos contra a deterioração de seu solo desgastado pelo uso contínuo e pela erosão das chuvas. No entanto, foi a nova representação de um processo que me permitiu cristalizar minhas reflexões em descrever, pela primeira vez, o processo econômico como uma conversão entrópica de valiosos recursos naturais (baixa entropia) em resíduos sem valor (alta entropia). Apresso em acrescentar.. que isso é apenas o lado material do processo. $O$ verdadeiro produto do processo econômico é um fluxo imaterial, o aproveitamento da vida, cuja relação com a transformação entrópica da matéria-energia é ainda misteriosa (GEORGESCUROEGEN, 1976, p. 14, Tradução dos autores).

A obra de Georgescu Roegen é, em vários aspectos, inovadora em relação às escolas rivais neoclássica e marxista. Embora diametralmente opostas, estas têm aspectos comuns, visto que ambas enfatizam o sistema de mercado urbano, capitalista e individualista e, a princípio, desconsideram os impactos ambientais da expansão urbano-industrial. A primeira porque é reducionista e abstrata, por natureza, a segunda porque, tendo como foco principal a história da teoria da luta de classes, está mais preocupada com a exploração do homem pelo homem do que com a degradação ambiental ${ }^{9}$.

\footnotetext{
De fato, Marx não teve tempo para presenciar as implicações ambientais da industrialização capitalista, que, em seu tempo, era certamente um problema bem menos visível do que as condições de vida da nascente classe operária. O hábito de negligenciar as questões ambientais dos marxistas que vieram depois parece também resultar da crença de que, ao final da história da luta de classes, todos os problemas da humanidade estarão resolvidos.
} 
Georgescu-Roegen e E.F. Schumacher estão entre os primeiros a perceber que o cálculo econômico é eticamente equivocado quando reduz os diversos tipos de inputs do processo produtivo a uma soma de custos, sem levar em conta certas diferenças essenciais entre as categorias envolvidas. Conforme Georgescu-Roegen, a atividade produtiva pode ser vista como um processo que requer a presença de três tipos diferentes de fatores que ele designou como 'de fundo', de 'fluxo' e de 'estoque'. Os fatores de fluxo são os materiais que entram no processo e, transformados pela ação dos fatores de fundo, saem incorporados no produto. Entre estes, há que se fazer também uma distinção entre os que podem ser repostos, como trabalho e capital, o primeiro pelo crescimento vegetativo da população e o segundo, pelos investimentos de reposição, e os que necessariamente se apresentam numa quantidade finita "nãoreproduzível", como é o caso da terra e dos estoques de combustíveis fósseis e outras matérias-primas minerais. Entretanto, em termos econômicos, nenhuma distinção é feita entre eles; todos têm um custo que é determinado pelos seus 'preços de mercado'. Assim, os fatores de estoque não-renováveis, como carvão mineral e petróleo, são tratados, pela geração presente, da mesma forma que os demais tipos, e seus preços determinados pelos respectivos 'custos de produção', de um lado, e pela demanda da geração presente, de outro. As necessidades energéticas de gerações futuras não são levadas em consideração ${ }^{10}$. Assim, ao ser determinado apenas pelas forças correntes de oferta e demanda, o preço desses fatores acaba sendo subestimado pela geração presente. Nesse caso, do ponto de vista de uma correta teoria econômica, o mercado falha na determinação do preço porque não consegue levar em conta a escassez, na sua devida dimensão $0^{11}$.

\footnotetext{
${ }^{10}$ No caso do preço do petróleo, por exemplo, entram em consideração apenas o custo da extração, de um lado, e a quantidade demandada, de outro. Quando, numa determinada conjuntura, a demanda cai, isso tem por efeito aumentar nos reservatórios o estoque de petróleo já extraído, instaurando uma tendência de redução do preço, e vice-versa. Se forem descobertas novas jazidas, mais acessíveis, o custo de extração tenderá a cair, associandose também a uma tendência de redução do preço, e vice-versa. Portanto, o preço do petróleo, cuja quantidade existente no planeta é fixa e que, portanto, um dia fatalmente chegará à completa exaustão, acaba sendo determinado da mesma forma que o de uma commodity agrícola, cuja produção pode ser mantida indefinidamente num fluxo contínuo, posto que depende apenas da existência de fatores de fundo e de fatores de fluxo nãoexauríveis.

11 Se o preço do petróleo incorporasse essa escassez "verdadeira", certas comodidades da vida moderna, como o automóvel particular, seriam economicamente inviáveis. O american way of life pode ser visto assim como uma distorção decorrente dessa falha.
} 
Outros interessantes insights de Georgescu-Roegen foram inspirados na observação de cenários socioeconômicos naturalmente baseados em comportamentos cooperativos e solidários, típicos de certas economias locais, de base agrícola, subdesenvolvidas e superpopulosas ${ }^{12}$. Se for para aplicar a técnica das funções de utilidade e de produção a estes cenários, deve-se estar preparado para levar em conta pelo menos duas grandes diferenças em relação ao habitual tratamento neoclássico. A primeira coisa a considerar é que o bem-estar de um indivíduo típico depende não apenas das suas possibilidades de consumo, mas também das possibilidades de consumo de sua comunidade. Formalmente, isso pode ser representado por uma função de utilidade $U=f(y, x)$, em que $y$ representa a capacidade de consumo próprio do indivíduo $(i)$ e $x$, os critérios particulares pelos quais ele considera o bem-estar comunitário. Sob as condições $f^{\prime}(y)>0$ e $f^{\prime}(x)>0$, essa função implica que a utilidade de um indivíduo não depende só da sua renda própria, mas também da distribuição da renda total entre os membros da comunidade. Esse tende a ser o caso de pequenas comunidades, onde cada membro conhece a situação dos demais e tem consciência das interdependências deles, em contraste com a função de utilidade do homem metropolitano, para o qual somente a variável $x$ é relevante, conforme o pressuposto neoclássico.

No entanto, nesses cenários, o critério da maximização de lucros também não faz sentido, uma vez que, dado o excesso de população em relação aos demais fatores de fundo, o objetivo da maximização da renda comunitária acaba sobrepujando qualquer objetivo individualista de maximização de lucro.

Ao que tudo indica, foi a consideração das características econômicas especiais desses cenários que inspirou Georgescu-Roegen a propor a analogia da física termodinâmica como mais adequada à economia do que à mecânica de Galileu e Newton. É certo que a humanidade, como um todo, está ainda longe de enfrentar as severas restrições já observadas

12 Tais cenários eram relativamente comuns no tempo de sua juventude na Romênia e outros países do leste europeu. 
em certas economias locais superpovoadas, nas quais se aplicam os princípios lógicos acima discutidos. Mas, se fosse devidamente considerado que, em decorrência da inevitável entropia positiva do processo econômico, é para um cenário desse tipo que a humanidade inexoravelmente convergirá, essa seria a perspectiva de maior sabedoria.

Não há dúvida que, em consonância com a segunda lei da termodinâmica, a atividade econômica do homo sapiens contribuiu para aumentar a entropia positiva do planeta, razão pela qual Georgescu-Roegen considerou a Lei da Entropia como "a de natureza mais econômica de todas as leis naturais". Os modos de vida, resultantes da industrialização "fordista", constituíram fatores agravantes disso, não apenas porque o "automóvel é muito mais 'entrópico' que a carruagem" e o "jumento é menos 'entrópico' que a motocicleta", mas também porque o processo de produção em massa difundiu o uso de órgãos "exossomáticos", como automóveis e motocicletas, aumentando, em consequência, a taxa de conversão de recursos naturais não renováveis em resíduos não recicláveis.

O fascínio provocado pelas "maravilhas tecnológicas", possibilitadas pela descoberta das leis da mecânica e do eletromagnetismo, de um lado, e a progressiva perda de contato do homem com "as maravilhas da natureza", em consequência da expansão urbano-industrial, de outro, contribuíram para a afirmação do modelo mecanicista na teoria econômica e para um modo de pensar que associa progresso a crescimento econômico, medido pela expansão do PIB. Do ponto de vista biológico, entretanto, tal mudança deve ser vista mais como ameaça do que como progresso da humanidade. Esse é outro insight notável de Georgescu-Roegen, que abre uma nova perspectiva para a ciência econômica, na qual se revela uma "essência biológica" da atividade econômica, em geral, e do desenvolvimento tecnológico, em particular. Essa é a razão pela qual, a partir da década de 70, essa nova perspectiva passou a ser designada como bioeconomia.

Georgescu-Roegen tomou emprestado do biólogo Alfred Lotka os termos exossomático, para designar os instrumentos e mecanismos artificiais que o homem inventa, e endossomático, para designar os órgãos físicos 
naturais dos seres vivos. Um leão, quando mata uma presa, conta apenas com órgãos endossomáticos como garras, mandíbula e dentes. Já o homem, para o fim de matar, costuma usar armas criadas por ele próprio. Essencialmente, o que distingue o ser humano das outras espécies animais é o fato de ele ser o único que utiliza capacidade cerebral para produzir órgãos "exossomáticos". Esta é a razão fundamental de ele ter se tornado a espécie dominante, dentre todas as outras formas de vida.

Os órgãos "exossomáticos" não são exclusivos dos seres humanos. Algumas espécies animais também se valem deles, como os pássaros, que fazem ninhos, e as abelhas, que constroem colmeias, por razões semelhantes às do homem, que constroi camas ou casas, mas o que distingue a espécie humana é a faculdade de produzir e inventar, incessantemente, órgãos "exossomáticos", não por instinto genético, como os pássaros e abelhas, mas pelo uso sistemático da razão. A espécie humana, como todas as demais espécies vivas está sujeito a um processo evolucionário endossomático, de acordo com a lei de Darwin. A diferença, em relação às demais espécies, é que a espécie humana evolui também por meios "exossomáticos".

Nesse sentido, a atividade econômica é uma extensão da atividade biológica. Os orgãos produzidos são utilizados e difundidos para sustentar um novo estilo de vida. Deste ponto de vista, a economia é essencialmente 'bioeconomia', pois envolve a evolução da existência do homem, como espécie, e não como indivíduo interessado apenas em maximizar o lucro (GEORGESCU-ROEGEN, 2003, p. 187-88, Tradução dos autores).

À medida que vem potencializar capacidades humanas, o desenvolvimento de órgãos "exossomáticos", como processo de "facilitação da vida", seja por meio de redução do esforço ou aumento do conforto e do prazer proporcionado ao homem, estabelece neste uma dependência viciosa. Outra consequência disso é a desigualdade na distribuição dos benefícios dessa evolução entre a classe que planeja, organiza, supervisiona e 
controla a produção, a que Galbraith (1977) chamou de tecnoestrutura, e a classe "dos que simplesmente participam dessa produção". Em outras palavras, para usar os termos de Georgescu-Roegen, o conflito entre "os que governam" e "os que são governados". A espécie humana revela, assim, outra característica diferenciadora das demais espécies, como ser biologicamente condicionado por processos biofísicos e ser social moldado por padrões institucionais.

O problema da dependência exossomática é que ela coloca a humanidade em rota de colisão com inevitáveis limites estabelecidos por uma dotação finita de recursos naturais, tendo em vista que, como Galbraith já havia demonstrado, é por meio de mecanismos que intensificam essa dependência que os membros da tecnoestrutura reafirmam seu poder de governança. Essa classe representa, assim, o papel do vilão na tragédia ambiental anunciada por Georgescu-Roegen.

\section{O imperativo categórico kantiano e o desenvolvimento sustentável}

O imperativo categórico kantiano pode ser formulado da seguinte maneira: ages de tal modo que a máxima das tuas ações possa se tornar uma lei universal, ou, ainda, ages de maneira que o motivo que te levou a agir assim possa ser convertido em lei universal.

Não preciso, pois, de perspicácia de muito largo alcance para saber o que hei de fazer para que o meu querer seja moralmente bom. Inexperiente a respeito do curso das coisas do mundo, incapaz de prevenção em face de acontecimentos que nele se venham a dar, basta que eu pergunte a mim mesmo:- Podes tu querer também que a tua máxima se converta em lei universal? (KANT, 2003, p.35). 
O imperativo categórico exige de todos os indivíduos o cumprimento do dever moral e fornece, para isso, o critério da lei universal, ou melhor, das máximas, segundo as quais as respectivas ações são praticadas (HAMM, 2003).

Scanlon (1998, p.153), no intuito de explicar o imperativo categórico e a lei universal kantiana, afirmou que

um ato é errado se sua realização nas circunstâncias atuais for desautorizada por qualquer conjunto de princípios para a regulação geral do comportamento que ninguém poderia rejeitar razoavelmente como uma base para o acordo geral esclarecido e não coagido (SCANLON, 1998, p.153).

Com o objetivo de tentar melhor exemplificar o imperativo categórico, Kant (2003) apresentou quatro exemplos: o suicídio, a mentira, o ocultamento dos talentos e a preocupação com o outro.

Kant (2003) tentou, primeiramente, explicar a lei universal e o imperativo categórico com a relação entre uma pessoa que se encontra com dificuldades extremas e pensa em suicidar-se. A partir daí, surge a primeira indagação kantiana, ou seja, se é possível transformar o suicídio em lei universal. Obviamente não, afirmou ele, visto que, por maiores que sejam as dificuldades, a morte jamais poderia ser a solução para os problemas.

O segundo ponto que Kant (2003) discutiu para esboçar o imperativo categórico é a mentira, ou seja, uma pessoa encontra-se em grandes dificuldades, tenta pedir dinheiro emprestado e diz que vai saldar a dívida em determinada data. Ela sabe que não vai poder honrar seu compromisso, mas, se não fizer isso, não conseguirá o dinheiro de que precisa. Daí, surge a segunda questão: Se é possível tornar a mentira uma lei universal, ou seja, se todos os homens deveriam mentir para alcançar seu objetivos. 
Em breve, reconheço que posso em verdade querer a mentira, mas que não posso querer uma lei universal de mentir; pois, segundo uma tal lei, não poderia proporcionalmente haver já promessa alguma, porque seria inútil afirmar a minha vontade relativamente às minhas futuras ações a pessoas que não acreditariam na minha afirmação, ou se, precipitadamente o fizessem, me pagariam na mesma moeda. Por conseguinte, a minha máxima, uma vez arvorada em lei universal, destruir-se ia a si mesma necessariamente (KANT, 2003, p.34).

O terceiro ponto, para fundamentar o imperativo categórico usado por Kant (2003), é o ocultamento dos talentos. Se uma pessoa tem determinadas habilidades e não se esforça para aperfeiçoá-las, isto não pode se tornar uma lei universal, pois, segundo Kant, esse comportamento não incentivaria as pessoas a aperfeiçoarem suas potencialidades e enfrentarem desafios.

Por fim, o último ponto que Kant (2003) explicitou é ilustrado no caso de uma pessoa que, ao ver um semelhante passando necessidades, em vez de ajudá-la a aliviar as dores, não faz absolutamente nada. Neste sentido, Kant (2003) questionou se a falta de solidariedade poderia se tornar uma lei universal. Não, pois sem qualquer solidariedade, a espécie humana não poderia subsistir.

Mendonça (2003) resumiu da seguinte forma o núcleo central da universabilidade e do imperativo categórico:

O núcleo razoável deste "teste da universabilidade das máximas" é o seguinte. Em muitos casos, podemos mostrar que uma opção é moralmente errada com um argumento que começa com a pergunta: "e se todos agissem dessa maneira?" Assim podemos mostrar que é errado pisar na grama, sonegar impostos e ou não honrar compromissos previamente assumidos. O teste 
kantiano nos fornece, portanto, na melhor das hipóteses, uma condição necessária para a escolha da moral (MENDONÇA, 2003, p.21).

Da definição de imperativo categórico surge a indagação sobre qual o critério para saber se a máxima individual deve se tornar uma lei universal e, aí, entra o conceito de boa vontade. Para Kant (2003), uma boa vontade é livre, autônoma, e as ações não são determinadas e nem causais. Dessa forma, são pré-requisitos para a ação do homem e para a definição de se o que ele está praticando poderia ser uma lei universal, contudo, muitas vezes, as opções e os atos dos homens fazem com que ele não tenha uma boa vontade. De acordo com Pascal (2005), no homem, muitas vezes, a vontade não é boa, devido às inclinações e à sensibilidade por determinadas coisas, atos e pessoas.

Com base nesses conceitos kantianos, pode-se fazer uma relação ao mesclar elementos da epistemologia acerca do desenvolvimento sustentável com os pressupostos filosóficos kantianos. Os homens sabem que o desenvolvimento sustentável é um pré-requisito fundamental para que as futuras gerações possam viver numa sociedade habitável, ou melhor, num planeta que seja sustentável do ponto de vista econômico, social, político e cultural. Então, por que a sociedade não tem uma preocupação com o desenvolvimento sustentável e não faz disso uma lei universal, aos moldes do imperativo categórico kantiano?

Começa-se a perceber o envolvimento de mais setores da sociedade que clama pela busca de soluções que levem em conta o desenvolvimento sustentável, como universidades, ONGs, organizações privadas e públicas, alguns governos e, ultimamente, até mesmo a mídia. Esse movimento, que vem avançando nos últimos anos, tem despertado a consciência de mais e mais indivíduos.

Entretanto, muito ainda é preciso avançar. Entra nessa questão um aspecto fundamental da ontologia kantiana, que é o conceito de boa vontade. As atitudes do homem, muitas vezes, não são inteiramente autônomas, visto que ele busca o lucro máximo, tem atitudes oportunistas, inclinado-se às 
ideologias, às vicissitudes, ao relativismo e às "modas do momento". Dessa forma, sua atitude, por tornar a busca pelo desenvolvimento sustentável uma lei universal, acaba ficando em segundo plano. Contudo, essa opção poderá comprometer o futuro das próximas gerações, que poderão ter que viver em ambientes inóspitos e insalubres, como consequência das atitudes de homens sem compromisso social, político e econômico com os seus semelhantes e com o planeta em que vivem.

Com base no exposto, torna-se evidente o forte vínculo entre os preceitos filosóficos kantianos e a bioeconomia de Georgescu-Roegen. A seguinte passagem, extraída de um de seus últimos textos, torna isso bem claro: "Uma nova ética emerge da bioeconomia e seu mandamento é: 'amai tua espécie como a ti mesmo'. (GEORGESCU-ROEGEN, 2003, p. 190, Tradução dos autores).

Sem ter, salvo engano, feito referência a Kant em seus escritos, a proposta de uma nova ordem econômica, de Georgescu-Roegen, que ficou conhecida como "programa bioeconômico mínimo", enquadra-se admiravelmente no espírito do imperativo categórico. O programa é composto por um conjunto de oito recomendações ${ }^{13}$, nas quais não há nada que já não tenha sido dito por pacifistas, críticos da sociedade de consumo, ecologistas ou filósofos existencialistas. A diferença é que não se fundamentam em nada que possa ser confundido com religião, ideologia ou romantismo, mas numa perspectiva econômica que, sem contrariar os cânones científicos mais aceitos, estabelece um ponto comum entre disciplinas distintas como a ética, biologia e economia.

Não obstante, Georgescu-Roegen estava ciente do elevado grau de "utopismo" da sua proposta. Era realista e cético quanto às possibilidades de aceitação de qualquer programa que apelasse para uma drástica redução do conforto material:

\footnotetext{
${ }^{13}$ Mas precisamente, o programa contém oito itens, entre as quais estão recomendações favoráveis a ajuda aos países subdesenvolvidos e ao agrarianismo, e contrárias à produção de armamentos, ao consumo conspícuo, ao marketing e a obsolescência tecnológica planejada.
} 
[...] Talvez, o destino da humanidade seja ter uma vida curta mas, ardente, excitante e extravagante, em vez de uma existência longa, porém monótona e vegetativa. Deixemos que outras espécies - as amebas, por exemplo, - que não têm ambições espirituais herdem uma terra ainda abundantemente ensolarada. (GEORGESCU-ROEGEN, 1976, p. 35, Tradução dos autores).

Ele também antecipou o reacionarismo das grandes potências para com as propostas de controle ambiental global, como bem demonstrou a posição do governo George Bush acerca do protocolo de Kyoto. A incursão bélica dos EUA no Oriente Médio parece também indicar bem a resposta para a indagação: "O que poderia decidir uma grande potência, armada com ogivas nucleares, se chegasse um tempo em não houvesse energia suficiente para manter operativo o seu sistema exossomático?" (GEORGESCU-ROEGEN, 2003, p. 190, Tradução dos autores).

\section{Considerações finais}

O objetivo geral deste artigo foi trazer a tona algumas reflexões sobre a questão do desenvolvimento sustentável, envolvendo economia, biologia e filosofia, em geral, e apresentar ideias de Nichollas Georgescu-Roegen que estabelecem notáveis pontos de contatos entre essas três disciplinas, em particular. Especificamente, procurou-se mostrar algumas ideias e propostas de um pensador cuja obra está sendo aos poucos resgatada, depois de longo ostracismo, certamente não ocasional, estabelecendo uma ligação com pressupostos analíticos da filosofia moral kantiana.

A busca pelo desenvolvimento sustentável, além de exigir mudanças de ordem cultural, política e econômica, exige também mudanças nas atitudes do homem, que precisará desenvolver uma visão mais complexa e mais multidisciplinar sobre esse desenvolvimento, visando proporcionar as condições para que as sociedades o alcancem. 
Os fundamentos da ética kantiana, apesar de terem sido formuladas há quase dois séculos, continuam atuais, visto que, se houver boa vontade dos homens, a busca pelo desenvolvimento sustentável poderia ser considerada como lei universal. Contudo, como advertiu Kant (2003), muitas vezes o homem, por suas atitudes, inclinações e preferências, não tem boa vontade. De certa forma, atualmente, é isso que ainda acontece com o desenvolvimento sustentável. É um conceito que ainda não é prioridade para a sociedade, em decorrência da busca e das inclinações do homem por outras coisas, como o lucro máximo e as "maravilhas exossomáticas" da sociedade pós-moderna.

\section{Referências}

ANTON, Wilma R. Q., DELTAS, George, KHANNA Madhu. Incentives for environmental self regulation and implications for environmental performance. Journal of Environmental Economics and Management, v.48, p.632-654, 2004.

ARISTÓTELES. Ética a Nicômaco. São Paulo: Martin Claret, 2004.

ARISTÓTELES. Política. São Paulo: Martin Claret, 2004.

BANERJEE, Subhabrata Bobby. Who Sustains Whose Development? Sustainable Development and the Reinvention of Nature. Organization Studies, v. 24, p. 143-180, 2003.

BANSAL, Pratima. Evolving sustainably: A longitudinal study of corporate sustainable development. Strategic Management Journal, v. 26, p. 197-218, 2005.

BARIN-CRUZ, Luciano; PEDROZO, Eugênio Ávila e ESTIVALETE, Vânia de Fátima Barros. Towards Sustainable Development Strategies: A complex view following the contribution of Edgar Morin. Management Decision, v.44, n.7, p.871-891, 2006. 
BUYSSE, Kristel e VERBEKE, Alain. Proactive Environmental Strategies: A stakeholder management perspective. Strategic Management Journal, v.24, n.5, p. 453-470, 2003.

CARSON, R. Primavera silenciosa. Madrid: Ed. Trotta S. A., 1962.

GALBRAITH, J. K. O novo estado industrial. São Paulo: Pioneira, 1977.

GEORGESCU-ROEGEN, N. The Entropy Law and the Economic Process, Cambridge, MA: Harvard University Press, 1971.

GEORGESCU-ROEGEN, N. Energy and Economic Myths, New York: Pergamon Press, 1976.

GEORGESCU-ROEGEN, N. Bioeconomia e etica. In BORINGHERI, B. (ed.) Bioeconomia.Torino: Corso Vittorio Emanuele II, Itália, 2003.

GLADWIN, Thomas N.; KENNELLY, James J.; KRAUSE, TaraShelomith. Shifting Paradigms for sustainable development: implications for management theory and research. Academy of Management Review, v. 20, n.4, p. 874-907, 1995.

GREAKER, Mads. Strategic environmental policy; eco-dumping or a green strategy? Journal of Environmental Economics and Management. v.45, p.692-707, 2003.

HAMM, Christian. Princípios, motivos e móbeis da vontade na filosofia prática kantiana. In: NAPOLI, Ricardo Bins di Napoli; ROSSATO, Noeli; FABRI, Marcelo (Orgs.). Ética e justiça. Santa Maria: Palloti, 2003.

LORETO, Élgion. Origem da vida e evolução. In: MOTA, Ronaldo et al. Método científico e fronteiras do conhecimento. Santa Maria: Ed. da UFSM, 2003.

KANT, Immanuel. Crítica da razão prática. São Paulo: Martin Claret, 2004. 
KANT, Immanuel. Fundamentação da metafísica dos costumes e outros escritos. São Paulo: Martin Clarim, 2003.

MENDONÇA, Wilson. Como deliberar sobre questões morais In: NAPOLI, Ricardo Bins di Napoli; ROSSATO, Noeli; FABRI, Marcelo (Orgs.). Ética e justiça. Santa Maria: Palloti, 2003.

MORIN, Edgar. O método 6: ética. Porto Alegre: Sulina, 2005.

NAPOLI, Ricardo Bins di. Ética e compreensão do outro. A ética de Wilhelm Dilthey sob a perspectiva do encontro interétnico. Porto Alegre: EDIPUCRS, 2000.

PASCAL, Georges. Compreender Kant. Petrópolis, RJ: Vozes, 2006. PLATÃO. A república. São Paulo: Nova Cultural, 2004.

RAWLS, J. A Theory of Justice. Cambridge: Harvard University Press, 2002.

RUSSO, Michael V. The emergence of sustainable industries: Building on natural Capital. Strategic Management Journal. v.24, n.4, p.317331,2003 .

SARTRE, Jean Paul. Existentialisme est un humanisme. Paris: Folio France, 1996.

SCANLON, T.M. What we one owe to each other ? Cambridge, Mas.: Harvard University Press, 1998.

SEITENFUS, Ricardo Antônio Silva; VENTURA, Deisy de Freitas Lima. (Orgs.) Um diálogo entre Einstein e Freud: por que a guerra? Santa Maria: Fadisma, 2005.

SHARMA, S.; HENRIQUES, I. Stakeholder Influences on Sustainability Practices in the Canadian Forest Products Industry. Strategic Management Journal, v.26, n.2, p.159-180, 2005. 
SCHUMACHER. E. F. O negócio é ser pequeno. São Paulo: Zahar, 1983.

SÓCRATES. Vida e pensamento. São Paulo: Martin Claret, 2002.

SPANGENBERG, Joachim H. Reconciling sustainability and growth: criteria, indicators, policies. Sustainable Development. v.12, p.74-86, 2004.

SPINELLI, Miguel. Filósofos pré-socráticos: primeiros mestres da filosofia e da ciência grega. Porto Alegre: EDIPUCRS, 1998.

SPINELLI, Miguel. Helenização e Recriação de Sentidos. A Filosofia na Época da Expansão do Cristianismo - Séculos II, III e IV. Porto Alegre: EDIPUCRS, 2002.

VÁZQUEZ. Adolfo Sánchez. Ética 28. ed. Rio de Janeiro: Civilização Brasileira, 2006.

WEBER, Max. A ética protestante e o espírito do capitalismo. Martin Claret, 2006.

WORLD COMMISSION ON ENVIRONMENT AND DEVElopMENT. Our Common Future. New York: Oxford University Press, 1987.

\footnotetext{
Abstract: The objective of this paper is to weave hermeneutic considerations and philosophies concerning ethics, economy and climate, with a specific focus on the relationship between Kant's categorical imperative and the question of improved sustainability. The economic perspective of Georgescu-Roegen has been considered, to this end. Although economy, ethics and biology constitute distinct fields of specialization, this work seeks to show reasons for which this perspective could be seen as an intersection between the three disciplines. The article concludes with the message of Georgescu-Roegan, held in his saying "minimal bioeconomic program" in accordance with the fundamental precepts of the Kantian ethics, in respect to the question of sustainability.
}

Keywords: ethics, sustainable development, Kant's, Georgescu-Roegen, bioeconomy. 
REVISTA DE ECONOMIA E AGRONEGÓCIO, VOL.7, $N^{o} 3$ 